\title{
Como medir o Sistema Solar: Situações didáticas com grandezas e medidas
}

\section{Roberta Chiesa Bartelmebs}

Doutoranda do Programa de Pós Graduação em Ensino de Ciências e Matemática da PUCRS, pesquisadora colaboradora do NUEPEC (FURG) e do LAPEF (PUCRS)

betachiesa@gmail.com

\section{Daiane dos Santos Beiersdorf}

Graduanda do curso de Pedagogia da Universidade Federal do Rio Grande daiadorf@hotmail.com

\section{Samanta Costa Calcagno}

Graduanda do curso de Psicologia da Universidade Federal do Rio Grande samantacalcagno@hotmail.com

\section{João Alberto da Silva}

Professor da Universidade Federal do Rio Grande joaosilva@furg.br

\begin{abstract}
Resumo
Apresentamos aqui uma proposta de atividade de aula com o objetivo de trabalhar com as crianças dos anos iniciais do Ensino Fundamental o bloco temático Grandezas e Medidas previstos pelos PCN Matemática (1997) e conteúdos referentes a Ciências e Estudos Sociais. A proposta foi dividida em três momentos em que o professor poderá explorar tanto os saberes prévios dos alunos como apresentar-lhes situações problemas em que precisem mobilizar seus conhecimentos e construírem novas relações com os conteúdos apresentados.
\end{abstract}

Palavras-chave: Grandezas e Medidas; Ensino de Matemática; Anos iniciais; Sistema Solar.

\section{Como medir o Sistema Solar: Situações didáticas com grandezas e medidas}

\begin{abstract}
Here we present a proposal for a class activity with the purpose of working with children from the early years of elementary school themed block Quantities and Measurements provided by the PCN Mathematics (1997) and content related to Science and Social Studies. The proposal was divided into three stages in which the teacher can explore both the prior knowledge the students how to present them in problem situations that require mobilizing their knowledge and build relationships with new contents.
\end{abstract}

Keywords: Quantities and Measurements; Mathematics Teaching; Early years; Solar System. 


\section{Apresentando o Projeto e a Proposta}

A proposta metodológica aqui apresentada configura-se como um projeto de trabalho e pesquisa realizado com crianças de 9 a 11 anos do $5^{\circ}$ ano de uma escola pública municipal, incluído em um projeto maior desenvolvido, e conta com o apoio do projeto Observatório Nacional da Educação (CAPES).

Trata-se da proposição de situações didáticas, nas quais se trabalham com os conteúdos de grandezas e medidas com a intenção de desenvolver atividades de pesquisa e trabalho coletivo, culminando com a construção de um móbile do sistema Sol - Terra - Lua.

\section{Apontamentos teóricos}

O ensino de matemática nos anos iniciais vem passando por diversas críticas, das quais as metodologias de ensino são questionadas sob a luz de diferentes vertentes epistemológicas. Para a vertente construtivista, baseada na epistemológica genética de Piaget (1983), as crianças aprendem através da ação sob os objetos. Isto é, aprendem pela experiência com o mundo. Essa experiência pode ser tanto física como lógico-matemática. Nesse sentido, compreendemos a aprendizagem como interação com o objeto de estudo, capaz de mobilizar o sujeito a construir conhecimentos a partir de suas experiências.

As atividades aqui sugeridas têm como objetivos potencializar o reconhecimento do espaço por parte das crianças, bem como identificar as distâncias e conseguir medi-las, conforme apontam os PCN (1997, p. 47): "Utilizar instrumentos de medida, usuais ou não, estimar resultados e expressá-los por meio de representações não necessariamente convencionais", potencializando assim tanto as experiências físicas de ação sobre os objetos da sala de aula ou escola, bem como a experiência lógico-matemática, na medida em que precisam realizar seus próprios cálculos e construírem suas próprias formas de medir e encontrar os resultados. Dessa forma contemplamos também outro objetivo apontado pelo PCN (idem) para o ensino de matemática nos anos iniciais do Ensino Fundamental que é o de possibilitar as crianças: "Perceber semelhanças e diferenças entre objetos no espaço, identificando formas tridimensionais ou bidimensionais, em situações que envolvam descrições orais, construções e representações".

Para desenvolver tais conteúdos o professor pode optar por trabalhar com situações problemas, pois, o trabalho com essa metodologia requer compreender que "o aprendizado matemático está completo quando o aluno é capaz de resolver problemas e de propor seus próprios problemas, entendendo como problema todo obstáculo que mereça ser analisado e ultrapassado" (DINIZ; SMOLE, 2001, p. 27). 
Nesse sentido, compreende-se que é preciso desenvolver nas crianças a capacidade de identificar problemas e resolvê-los, e ainda criar os seus próprios problemas, uma vez que é a partir deles que se podem trabalhar vários conteúdos de forma integrada. Além disso, as crianças também são estimuladas a pensarem em hipóteses sobre os problemas e desafios que lhes são oferecidos, muitas dessas hipóteses que as crianças formulam estão baseadas em vivências próprias, e aprendizagens anteriores. Isso por sua vez contribui para que por meio da problematização e criação de hipóteses, novas aprendizagens sejam adquiridas.

\section{A proposta de atividade}

As atividades sugeridas podem ser desenvolvidas em várias aulas, podendo ser também integradas com outros conteúdos tais como Ciências, História, Geografia. Neste caso integramos o conhecimento matemático das distâncias e proporções ao assunto Sistema Solar, trabalhando com as crianças as distâncias e os tamanhos dos astros.

\section{$1^{\circ}$ Momento da situação didática:}

A primeira atividade proposta é a de dividir a turma em pequenos grupos e propor-lhes algumas situações problemas sobre distâncias e medidas de espaços escolares, tais como: a) Qual a distância da sala de aula até o refeitório? b) Qual a distância da sala até a biblioteca? c) Qual a distância da sala até os banheiros? Etc.

A partir disso, solicita-se que realizem diferentes medições pela escola. Cada grupo fica responsável por um trajeto, por exemplo: Medir a distância da sala de aula até o refeitório ou banheiros ou mesmo a biblioteca. Nessa atividade as crianças irão explorar diferentes modos de realizar as medidas, utilizando-se do próprio corpo (passos, mãos, pés) ou ainda de instrumentos de medida como réguas, trenas ou fita métrica. Sugere-se que o professor deixe-as livres e observe como realizam essas medidas. Depois disto, o grupo deverá registrar seus resultados e problematizar com seus colegas os resultados obtidos. O professor poderá aproveitar a oportunidade para trabalhar com os instrumentos de medidas, os cálculos de área e perímetro etc. Para finalizar a atividade e prepará-los para as próximas etapas, sugere-se levantar questões do tipo: "Qual o tamanho do Sol? Qual o tamanho da Lua? Qual o tamanho da Terra?" O professor pode solicitar um desenho sobre essa temática para coletar informações dos conhecimentos prévios das crianças sobre como representam tais astros em termos de tamanho e distâncias. Nesse momento a representação bidimensional facilitará ao professor visualizar e compreender as ideias prévias que as crianças apresentam sobre essa temática. 


\section{$2^{\circ}$ Momento da situação didática:}

Neste momento, sugere-se propor aos alunos a construção de uma maquete da sala de aula. Avança-se nesse momento para uma representação tridimensional após o trabalho com os espaços em que as crianças convivem na escola. Sugere-se que o trabalho com a tridimensionalidade venha antes do trabalho com a representação bidimensional, pois, a criança terá mais chances de interagir com objetos tridimensionais para conhecer suas propriedades do que iniciando o trabalho com um desenho ou representação. Novamente em pequenos grupos, recebem diferentes tarefas: construir uma maquete das classes, das cadeiras, armários, janelas e portas, quadro negro e outros objetos presentes na sala de aula. O professor precisa orientar os grupos a realizarem as medidas dos objetos reais e do material que eles possuem para representar esses objetos. Não se dirá ainda aos alunos como realizar o cálculo de proporção, mas já se pode trabalhar como eles estão observando a existência ou não de proporções nos objetos da sala de aula. Depois de cada grupo realizar essa maquete, deve-se unir os objetos em uma placa de "isopor" ou de papel para visualizarem os objetos representados. A problematização será certamente a ausência de uma escala conjunta, o que levará a maquete a ter diferentes tamanhos e proporções. Isso pode ser muito proveitoso para se discutir com as crianças, promovendo assim um problema a ser solucionado no passo seguinte do projeto: Será possível construir uma maquete ou móbile que represente o Sol, a Terra e a Lua em escala?

\section{$3^{\circ}$ Momento da Situação Didática:}

Neste momento as crianças deverão ser encaminhadas a pequenas pesquisas a respeito do Sistema Solar. Essa pesquisa pode ser feita tanto pelo professor (no caso de os alunos não terem acesso a rede de computadores com internet) ou pelas crianças no espaço do laboratório de informática da escola. Após a pesquisa, poderão realizar uma espécie de seminário ou apresentação, para que todos possam expressar seus conhecimentos atuais a respeito das escalas e das proporções presentes no Sistema Solar. O professor também poderá trabalhar com mapas geográficos e políticos, globos terrestres e até mesmo com o site Google Maps ou Google Earth ou ainda com softwares como Celestia e Stellarium para apresentar aos alunos diferentes formas de se representar os objetos do Sistema Solar.

A proposta final deste projeto é a construção de um móbile do sistema Sol-Terra-Lua, em escala e proporções reais. O desafio será que os alunos trabalhem em equipe, realizem os cálculos e cheguem as reais medidas. Para isso, o professor poderá dividir a turma em equipes, onde cada uma fique responsável pela confecção de uma parte da escola, porém os cálculos deverão ser feitos coletivamente para que todos possam ter os mesmos padrões de medidas e utilizem a mesma escala e 
proporções em suas maquetes. Pode-se fazer uso de uma escala já estabelecida, como a que se encontra no livro da coleção explorando o ensino: Astronomia (NOGUEIRA, CANALLE, 2009, p.85). Quando o trabalho estiver concluído, sugerimos que haja uma exposição para que toda a comunidade escolar possa apreciar o trabalho desenvolvido pela turma.

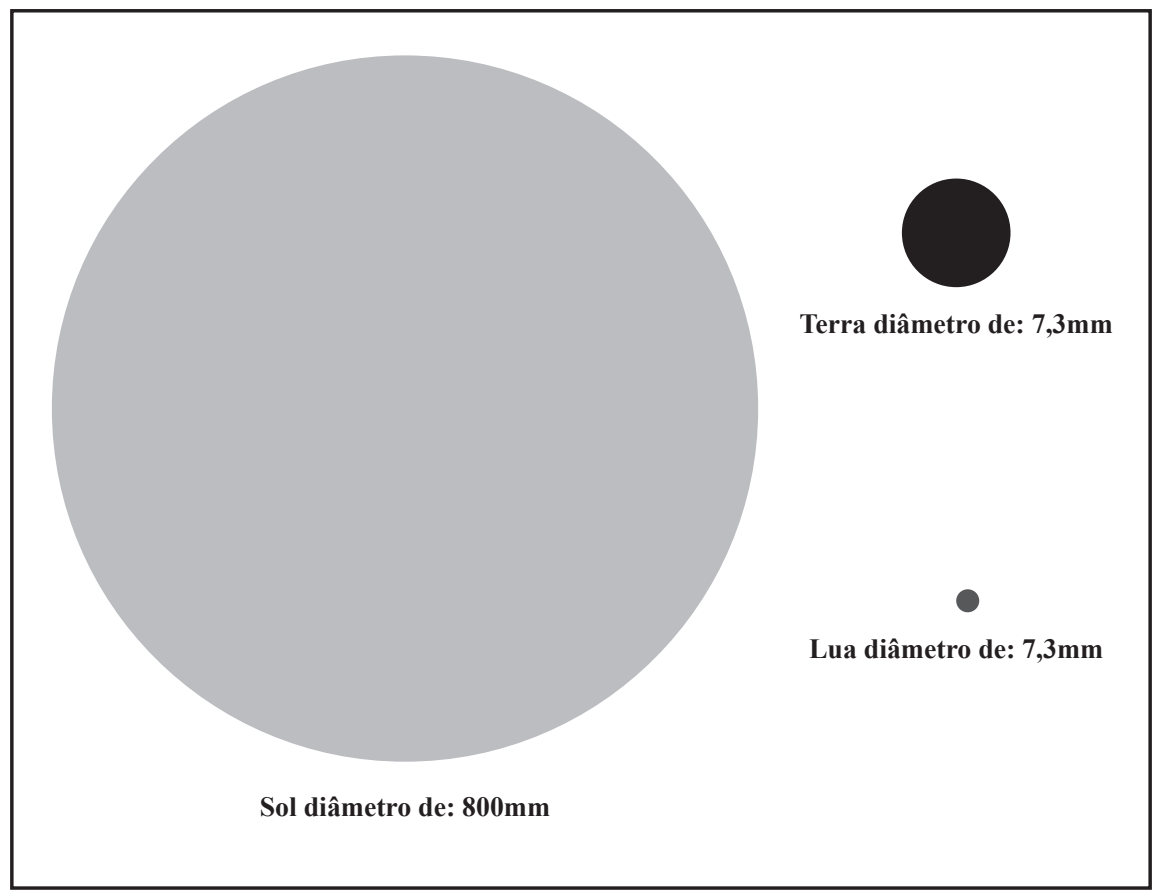

Figura 1 - Adaptação da representação das escalas presentes em (NOGUEIRA, CANALLE, 2009, p.82) utilizadas na construção do móbile.

\section{Considerações Finais}

O ensino de matemática pode ser uma tarefa bastante criativa e interessante para as crianças. Podemos perceber na confecção das maquetes e nas diferentes situações problemas apresentadas que as crianças poderão mobilizarem-se de diferentes maneiras para aprenderem um mesmo conteúdo.

Além disso, o trabalho coletivo como instrumento de organização metodológica pode por exigir aprendizagens que vão além das conceituais, potencializar aprendizagens atitudinais e procedimentais, tais como o respeito ao colega no trabalho em equipe e a própria confecção de uma maquete. 
Por fim, também possibilitamos as crianças comunicarem suas diferentes estratégias para resolver situações-problema, por entendermos que isso facilita o aprendizado e favorece que o aluno perceba o ponto de vista do próximo:

Falar sobre Matemática, escrever textos sobre conclusões, comunicar resultados, usando ao mesmo tempo elementos da língua materna e alguns símbolos matemáticos, são atividades importantes para que a linguagem matemática não funcione como um código indecifrável para os alunos (BRASIL, 1997, p.46).

Assim também se desmitifica que a matemática é algo abstrato, formal e difícil de aprender. Se as crianças elaboram seus conhecimentos e os veem sendo valorizados no decorrer das aulas de matemática, poderão identificar formas diferentes de se chegar a resultados ou soluções para inúmeros problemas. Nesse sentido, é preciso compreender a matemática como uma linguagem não apenas embasada em números, mas de forma mais ampla como a capacidade de comunicar um resultado, e que tal comunicação pode ser feita de diferentes formas sem que se esteja deixando de lado a linguagem matemática.

\section{Referências}

SMOLE, Kátia Stocco; DINIZ, Maria Ignez. Ler, escrever e resolver problemas: Habilidades básicas para aprender matemática. Porto Alegre: Artmed Editora, 2001.

BRASIL, Secretaria de Educação Fundamental. Parâmetros Curriculares Nacionais: Matemática. Brasília: MEC/SEF, 1997.

PIAGET, Jean. A epistemologia genética: Sabedoria e ilusões da filosofia: Problemas de psicologia genética. $2^{\text {a }}$ Ed. São Paulo: Abril Cultural- Coleção Os Pensadores, 1983.

NOGUEIRA, Salvador. CANALLE, João Batista Garcia. Astronomia: Ensino Fundamental e Médio. Coleção Explorando o Ensino vol. 9. Brasília: MEC, SEB, MCT, AEB, 2009. 